\title{
Ultrasonographic Evaluation of Intima Media Thickness of Carotid Arteries among Hypertensive and Hypertensive with Diabetes Mellitus
}

\author{
Kada Venkata Ramana ${ }^{1}$, T. Rajesh Kumar ${ }^{2}$ \\ ${ }^{1}$ Associate Professor, Department of Radiology, Konaseema Institute of Medical Science, Amalapuram, Andhra Pradesh, \\ ${ }^{2}$ Assistant Professor, Department of Radiology, Konaseema Institute of Medical Science, Amalapuram, Andhra Pradesh, India
}

Corresponding author: Dr. T. Rajesh Kumar, Assistant Professor, Department of Radiology, Konaseema Institute of Medical Science, Amalapuram, Andhra Pradesh, India

DOI: http://dx.doi.org/10.21276/ijcmsr.2019.4.3.34

How to cite this article: Kada Venkata Ramana, T. Rajesh Kumar. Ultrasonographic evaluation of intima media thickness of carotid arteries among hypertensive and hypertensive with diabetes mellitus. International Journal of Contemporary Medicine Surgery and Radiology. 2019;4(3):C158-C161.

\section{A B S T R A C T}

Introduction: Ultrasonographic evaluation of carotid intima media thickness is a non-invasive method to assess the manifestation of atherosclerosis and also used to predict the early stage of cardiovascular diseases. Keeping these in view we have deigned this study to measure the carotid intima media thickness in patients with hypertension and diabetes with hypertension to correlate between these groups and to know which group is more prone for cardiovascular diseases and atherosclerosis.

Material and Methods: As per inclusion and exclusion criteria 120 patients were selected, with 60 patients each in hypertension $(\mathrm{gr} \mathrm{H}$ ) and hypertension with diabetes mellitus (gr HD) patients particulars like age, sex, weight, body mass index, fasting plasma glucose, and post prandial plasma glucose was estimated Serum total cholesterol, LDL, HDL and TG was also measured. $\mathrm{HBA}_{\mathrm{c}}$ was also measured on all patients. For measurement of carotid in time media thickness we used Philips clear view 650 ultra sound with linear probe having $8 \mathrm{MH} 8$ solution. Unpaired T test and chi square test was used for comparison of data and $\mathrm{P}$ value less than 0.05 were considered significant.

Result: Thickness of Rt. Common carotid in group $\mathrm{H}$ was $0.716 \pm 0.03 \mathrm{~mm}$ and in group HD it was $0.8495 \pm 0.07$ having $\mathrm{P}$ value 0.0001.Thickness of carotid intima and media was $0.723 \pm 0.183$ in group $\mathrm{H}$ in left carotid artery. But left carotid intima media thickness in group HD was $0.8495 \pm 0.07 \mathrm{~mm}$. The $P$ value was 0.0001 . The mean of carotid intima media thickness of right internal carotid artery in group $\mathrm{H}$ was $0.642 \pm 0.432 \mathrm{~mm}$ and the $\mathrm{P}$ value was 0.007 .

Conclusion: CIMT was significantly higher in patient suffering from diabetes mellitus and hypertension then hypertension alone. This indicate that diabetes along with hypertension accelerate the atherosclerosis process.

Keywords: Carotid Intima Media Thickness, Hypertension, Diabetes Mellitus

\section{INTRODUCTION}

Cardio vascular diseases are the number one cause of death globally. In year 2016, 17.9 million people died from cardiovascular diseases that are $31 \%$ of all global death. Out of these $85 \%$ is due to stroke and heart attack. People who are at high risk need early detection and management to prevent these deaths. ${ }^{1}$ Cardio vascular diseases are clinical manifestation of atherosclerosis. Carotid arteries are the vessels which develop atherosclerosis in the presence of risk factor like hypertension and diabetes. Association between increase in thickness of intima-media of carotid artery and cardio vascular diseases are well established.(2) Independent of other risk factor a positive association exist between carotid intima media thickness and subsequent cardio vascular event.(3) However the relation between the progress of CIMT(carotid intima media thickness) and cardio vascular events are not clear. Goldberger $\mathrm{ZD}$ et $\mathrm{al}^{4}$ has reported a positive association metaanalysis. But Lonenz $\mathrm{MV}$ et al and Costanzop et al. ${ }^{3,5}$ have reported no association between the two. Vijay Nambi and Llyod chambless et $\mathrm{al}^{6}$ in his atherosclerosis risk in community study (ARIC) has concluded that carotid USG based carotid intima media thickness measurement and identification of plaque presence or absence improves coronary heart diseases predication risk. It has been observed that the thickness of carotid intima -media used to be significantly higher in diabetic and hypertensive patients. ${ }^{7,8}$ Hence Ultrasonographic evaluation of carotid intima media thickness is a non-invasive method to assess the manifestation of atherosclerosis and also used to predict the early stage of cardiovascular diseases. Keeping these in view we have deigned this study to measure the carotid intima media thickness in patients with hypertension and diabetes with hypertension to correlate between these groups and to know which group is more prone for cardiovascular diseases and atherosclerosis. 


\section{MATERIAL AND METHODS}

This was a cross sectional hospital based study conducted in the department of Radiology Konaseema institute of medical science Amalapuram, Andhra Pradesh form August 2016 to January 2019. Present study was approved by institutional ethics committee. A written informed consent was obtained from all patients before we enrol them for study.

\section{Selection criteria of patients}

Inclusion criteria

- $\quad$ Age 30 to 60 yrs

- Both sex

- Hypertension patients and patients with Hypertension and DM

\section{Exclusion criteria}

- Patient with complication of DM

- Type 1 DM

- Cardiovascular and respiratory Complication

- Pregnancy and lactation

Sample size and sampling method: Based on the data of previous studies regarding incidence and prevalence of disease, and assuming the power of study $80 \%$ and error $0.03 \%$ sample size of calculated to be $60^{9,10}$ we used purposive sampling for selection of sample.

Method: As per inclusion and exclusion criteria 120 patients were selected, with 60 patients each in hypertension ( $\mathrm{gr} \mathrm{H}$ ) and hypertension with diabetes mellitus ( $g r$ HD) patients particulars like age, sex, weight, body mass index, fasting plasma glucose, and post prandial plasma glucose was estimated Serum total cholesterol, LDL, HDL and TG was also measured. $\mathrm{HBA}_{\mathrm{C}}$ was also measured on all patients. Diagnosis of hypertension and diabetes was based on JNC 8 and American diabetes association guidance. ${ }^{11,12}$ Blood pressure was measured by mercury sphygmomanometer. For estimation glucose we used hexokinase method, total cholesterol was measured by Liebermann Bunchard reaction,
Neri and fringe method was used for estimation of triglyceride, HDL concentration was measured by precipitation method. LDL was calculated by WHO formula LDL chol = total cholesterol - TG/5 - HDL (mg/dl). HbAlc was estimated by spectrophotometer. For measurement of carotid in time media thickness we used Philips clear view 650 ultra sound with linear probe having $8 \mathrm{MH} 8$ solution.

\section{STATISTICAL ANALYSIS}

Data collected and tabulated on excel sheet for analysis of data we used SPSS version 16 software. Unpaired T test and chi square test was used for comparison of data and $\mathrm{P}$ value less than 0.05 were considered significant.

\section{RESULT}

As per inclusion and exclusion criteria 120 patient were enrolled for this study during two and half year of study period. Out of 120 patients, 60 patients were suffering from hypertension and remaining 60 patients were suffering from hypertension and diabetes mellitus.

In group $(\mathrm{H})$ as per table $\mathrm{I}$ the mean age of the patient was $49.76 \pm 7.69$ yrs and group HD it was $49.12 \pm 9.58$ years there was no significant difference between two groups with respect to age, the $\mathrm{P}$ value was 0.385629 . Weight of the patient in two groups were $83.43 \pm 12.40 \mathrm{~kg}$ and $82 \pm 13.72$ kgs. Both the group were similar to each other with respect to weight of the patient $(\mathrm{P}=0.340)$. There was no significant difference between two group with respect to sex ratio $(\mathrm{M}: \mathrm{F}=$ 48:12 in group $\mathrm{H}, \mathrm{M} ; \mathrm{F}=44: 16$ in group $\mathrm{HD})(\mathrm{p}=0.7453)$. Mean of body mass index was little higher in group HD that is $26.413 \pm 3.43 \mathrm{~kg} / \mathrm{ml}$ then group $H$ that is $25.94 \pm 2.76 \mathrm{~kg} /$ $\mathrm{m}^{2}$. Both groups are comparable to each other.

As per table-2 regarding comparison of metabolic parameters, between two group fasting plasma glucose was significantly higher in group HD than group $\mathrm{H}$ that is $(131.5 \pm 13.12 \mathrm{mg} /$ $\mathrm{dl}$ vs $85.66 \mathrm{mg} / \mathrm{dl})$. The $\mathrm{P}$ value was 0.0001 .Post prandial plasma glucose was $129.46 \pm 10.42 \mathrm{mg} / \mathrm{dl}$ in group $\mathrm{H}$ but it
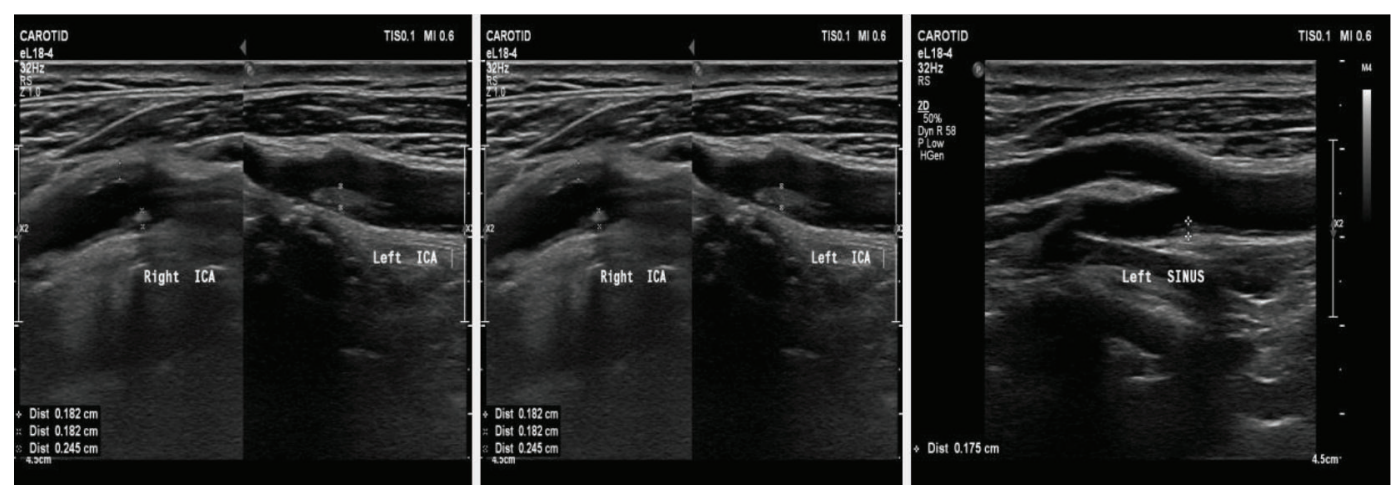

Figure-1: Showing carotid intima media thickness of CCA(Common carotid artery) and ICA(internal carotid artery)

\begin{tabular}{|l|c|c|c|}
\hline Variables & Gr H & Gr HD & P value \\
\hline Mean Age (Yrs) & $49.76 \pm 7.69$ & $49.1 \pm 9.58$ & 0.385629 \\
\hline Weight (Kgs) & $83.43 \pm 12.40$ & $82 \pm 13.72$ & 0.340 \\
\hline \multirow{2}{*}{ Sex ratio M/F } & 48 & 44 & 0.387955 chi square state 0.7453 \\
\cline { 2 - 4 } & 12 & 16 & 0.285261 \\
\hline BMI $\left(\mathrm{kg} / \mathrm{m}^{2}\right)$ & $25.94 \pm 2.76$ & $26.413 \pm 3.42$ & \\
\hline \multicolumn{2}{|r|}{} \\
\cline { 2 - 4 }
\end{tabular}




\begin{tabular}{|l|c|c|c|}
\hline Variables & Gr H & Gr HD & P value \\
\hline FPG $(\mathrm{mg} / \mathrm{dl})$ & $85.66 \pm 15.544$ & $131.5 \pm 13.12$ & 0.00001 \\
\hline PPBG $(\mathrm{mg} / \mathrm{dl})$ & $129.46 \pm 10.42$ & $209.67 \pm 9.824$ & 0.00001 \\
\hline $\mathrm{HDL}(\mathrm{mg} / \mathrm{dl})$ & $34.16 \pm 3.97$ & $31.78 \pm 2.84$ & 0.077 \\
\hline $\mathrm{LDL}(\mathrm{mg} / \mathrm{dl})$ & $124.04 \pm 5.40$ & $154.69 \pm 19.44$ & 0.0081 \\
\hline $\mathrm{CHOL}(\mathrm{mg} / \mathrm{dl})$ & $208.5 \pm 22.32$ & $232.46 \pm 23.76$ & 0.018477 \\
\hline TG $(\mathrm{mg} / \mathrm{dl})$ & $180.20 \pm 7.76$ & $190 \pm 9.01$ & 0.0039 \\
\hline $\mathrm{HbAc}(\%)$ & $4.68 \pm 0.39$ & $6.53 \pm 0.429$ & 0.00001 \\
\hline SBP $(\mathrm{mm}$ of HG) & $151.167 \pm 8.44$ & $152.896 \pm 8.94$ & 0.2278 \\
\hline DBP $(\mathrm{mm} / \mathrm{HG})$ & $96.42 \pm 6.78$ & $95.682 \pm 7.32$ & 0.0732 \\
\hline \multicolumn{2}{|r|}{ Table-2: Comparison of metabolic parameters in two groups. } \\
\hline
\end{tabular}

\begin{tabular}{|l|l|c|c|c|}
\hline Carotid artery & & Gr H & Gr C HD & P value \\
\hline \multirow{2}{*}{ Common Carotid $(\mathrm{mm})$} & $\mathrm{Rt}$ & $0.716 \pm 0.03$ & $0.8495 \pm 0.07$ & 0.0001 \\
\cline { 2 - 5 } & $\mathrm{Lt}$ & $0.723 \pm 0.183$ & $0.8843 \pm 0.057$ & 0.0001 \\
\hline \multirow{2}{*}{ Internal Carotid $(\mathrm{mm})$} & $\mathrm{Rt}$ & $0.642 \pm 0.432$ & $0.824 \pm 0.43$ & 0.007 \\
\cline { 2 - 5 } & Lt & $0.682 \pm 0.392$ & $0.782 \pm 0.43$ & 0.002 \\
\hline
\end{tabular}

was $209.67 \pm 98.24 \mathrm{mg} / \mathrm{dl}$ group $\mathrm{HD}$, which is significantly statistically $(\mathrm{p}=0.0001)$. The mean value HDL was $34.16 \pm 3.97$ $\mathrm{mg} / \mathrm{dl}$ in group $\mathrm{H}$, and $31.78 \pm 2.84 \mathrm{mg} / \mathrm{dl}$ in group HD. The $\mathrm{P}$ value was 0.077 . The mean conc of $\mathrm{LDL}$ was $124.04+5.40$ $\mathrm{mg} / \mathrm{dl}$ in group $\mathrm{H}$ and $154.69 \pm 19.44 \mathrm{mg} / \mathrm{dl}$ in group HD. The $\mathrm{P}$ value was 0.0081 , which is significantly statistically. Total cholesterol mean conc in group $H$ was $208.5+22.32$ $\mathrm{mg} / \mathrm{dl}$ and group HD it was $209.67 \pm 9.84 \mathrm{mg} / \mathrm{dl}$. Which was significantly different from each other as $\mathrm{P}$ value was 0.018 which is more than 0.05 . In group $H$ mean value of $T G$ was180.20=7.76 mg/dl and in group HD it was $190 \pm 9.01$ $\mathrm{mg} / \mathrm{dl}$. This difference in TG value is significantly statistically as $\mathrm{P}$ value is 0.018 . Glycosylated haemoglobin $\left(\mathrm{HBA} 1_{\mathrm{C}}\right.$ ) was $4.68 \pm 0.3 \%$ in group $\mathrm{H}$ and $6.53 \pm 0.429 \%$ in group HD. The $\mathrm{P}$ value was 0.00001 . Both group were comparative to each other respect to systolic and diastolic blood pressure as the $\mathrm{P}$ value was more than 0.05 .

Regarding comparison of thickness of carotid intima and media, as per table- 2 thickness of Rt. Common carotid in group $\mathrm{H}$ was $0.716 \pm 0.03 \mathrm{~mm}$ and in group $\mathrm{HD}$ it was $0.8495 \pm 0.07$ having $\mathrm{P}$ value 0.0001 . Thickness of carotid intima and media was $0.723+0.183$ in group $\mathrm{H}$ in left carotid artery. But left carotid intima media thickness in group HD was $0.8495 \pm 0.07 \mathrm{~mm}$. The $\mathrm{P}$ value was 0.0001 . The mean of carotid intima media thickness of right internal carotid artery in group $\mathrm{H}$ was $0.642 \pm 0.432 \mathrm{~mm}$ and the $\mathrm{P}$ value was 0.007 . Similarly there was significantly difference between left common carotid artery intima media thickness between two groups as the $\mathrm{P}$ value was 0.002 .

\section{DISCUSSION}

Carotid intima media thickness was evaluated in hypertensive and diabetes patient with hypertension by using ultrasound. Sixty patients were included in each group and study was conduction for two years and five months. Both the group were comparable to each other with respect to age, sex ratio and body weight, The Pvalue was more than 0.05 . This finding corroborates with the finding of Naseh $\mathrm{G}$ et al and E.S. Lee et al. ${ }^{9,13}$ The body mass index was little higher in diabetes group but not significant statistically this is supported by the work of Gayathri et al. ${ }^{14}$

Regarding comparisons of various metabolic parameters FPG and PPPG was significantly higher in diabetic group with $\mathrm{P}$ value more than 0.00001 . This finding corroborates with the study of Basil, Okeahialam et al. ${ }^{15}$

Regarding the mean of lipid profile of two groups we have found that LDL, TG and total Chol was high in both groups but is significantly higher in diabetes plus hypertension group than hypertension alone. The mean value of $\mathrm{HDL}$ was also low in both groups but it was comparable to each other in both groups as the $\mathrm{P}$ value was 0.07 . This finding is supported by the work of Maria matsagoura et al but not corroborates with the finding of Louise landby et al. ${ }^{16,17}$ There is no significant difference between mean of SBP and DBP in both groups. $(\mathrm{P}=0.22$ for $\mathrm{SBP}$ and $\mathrm{P}=0,732$ for $\mathrm{DBP})$. The study of Gomez mancos MA et al supports our study. ${ }^{18}$

Regarding thickness of common carotid artery on both sides, it is high in both groups but it is significantly higher in diabetes group than hypertensive group. Which supported by the work of E.J. lee et al, Gauarfm R et al. and Naseh $\mathrm{G}$ et al. ${ }^{9,13,14}$ Bonithon koppc et al in his study concluded that diabetes and hypertension is associated with increase in carotid intima media thickness. Together they increase the progress of thickness which supports our study. ${ }^{19}$ Naseh G et al and Malkinnon et al in his study found that internal carotid artery intima media thickness was higher in study group which support our study. ${ }^{9,20}$

Adaikkappan M, Sampath R et al from his study has stated that the intima media thickness of carotids as assessed by Ultrasonographic study was significantly increased in all hypertensive patients when compared with normotensives. ${ }^{21}$ This finding support our study. Kota S K et al has stated that People with diabetes have higher CIMT than the healthy population and simultaneous hypertension is associated with independently and significantly related to CIMT. He has further concluded that CIMT can be used as a valuable routine screening tool for the evaluation of atherosclerosis in T2DM patients. ${ }^{22}$ This finding supports our study. 


\section{CONCLUSION}

In present study we conclude that patient suffering from diabetes and hypertension and hypertension alone have dyslipidaemia. The carotid intima media thickness was high in both groups in both common carotid and internal carotid artery. CIMT was significantly higher in patient suffering from diabetes mellitus and hypertension then hypertension alone. This indicate that diabetes along with hypertension accelerate the atherosclerosis process.

\section{REFERENCES}

1. Fact sheets, Cardiovascular diseases (CVDs), 17 May 2017,World health organisation, downloaded from, https://www.who.int/news-room/fact-sheets/detail/ cardiovascular-diseases-(cvds).

2. Vijay Nambi, Claudia Pedroza, Lillian S Kao. Carotid intima-media thickness and cardiovascular events The Lancet 2012;379(1):P2028-2030.

3. Lorenz MW, PolakJF, Kavousi M, et al. Carotid intimamedia thickness progression to predict cardiovascular events in the general population (the PROG-IMT collaborative project): a meta-analysis of individual participant data [published correction appears in Lancet. 2012;380(9840):474]. Lancet. 2012;379(9831):20532062.

4. Goldberger ZD Valle JA Dandekar VK Chan PS Ko DT Nallamothu BK. Are changes in carotid intimamedia thickness related to risk of nonfatal myocardial infarction? A critical review and meta-regression analysis. Am Heart J. 2010; 160(3): 701-714.

5. Costanzo P,Perrone-Filardi,P Vassallo E et al.Does carotid intima-media thickness regression predict reduction of cardiovascular events? A meta-analysis of 41 randomized trials.J Am Coll Cardiol. 2010; 56(2): 2006-2020.

6. Nambi V, Chambless L, Folsom AR, et al. Carotid intima-media thickness and presence or absence of plaque improves prediction of coronary heart disease risk: the ARIC (Atherosclerosis Risk In Communities) study. J Am Coll Cardiol. 2010;55(15):1600-1607.

7. del Sol AI, Moons KG, Hollander M, et al. Is carotid intima-media thickness useful in cardiovascular disease risk assessment? The Rotterdam Study Stroke. 2001;32(6):1532-1538.

8. Chambless LE, Folsom AR, Sharrett AR, et al. Coronary heart disease risk prediction in the Atherosclerosis Risk in Communities (ARIC) study. J Clin Epidemiol. 2003;56(3):880-890.

9. Naseh G, Fard MM, Kazemi T, Mirgholami A, Hashemi N, Saburi A. Comparison of Carotid Intimamedia Thickness in Hypertensive Patients and Control Group. J Cardiovasc Echogr. 2016;26(2):48-51.

10. Sample Size Calculator, downloaded from https://www. calculator.net/sample-size-calculator.html

11. James PA, Oparil S, Carter BL, Cushman WC, Dennison-Himmelfarb C, Handler J, et al. 2014 evidence-based guideline for the management of high blood pressure in adults: Report from the panel members appointed to the Eighth Joint National Committee (JNC 8) JAMA. 2014;311(1):507-20.
12. American Diabetes Association. 2. Classification and diagnosis of diabetes: Standards of Medical Care in Diabetes-2018. Diabetes Care 2018;41(Suppl. 1):S13-S27

13. E.J. Lee, H.J. Kim, J.M. Bae, J.C. Kim, H.J. Han, C.S. Park, N.H. Park, M.S. Kim and J.A. Ryu Relevance of Common Carotid Intima-Media Thickness and Carotid Plaque as Risk Factors for Ischemic Stroke in Patients with Type 2 Diabetes Mellitus American Journal of Neuroradiology May 2007;28 (5):916-919;

14. R Gayathri, R Chandni, V Udayabhaskaran. Carotid Artery Intima Media Thickness in Relation with Atherosclerotic Risk Factors in Patients with Type 2 Diabetes Mellitus. J Assoc Physicians India. 2012;60(4):20-4.

15. Basil N. Okeahialam, Benjamin A. Alonge, Stephen D. Pam, and Fabian H. Puepet. Carotid Intima Media Thickness as a Measure of Cardiovascular Disease Burden in Nigerian Africans with Hypertension and Diabetes Mellitus. International Journal of Vascular Medicine, vol. 2011, Article ID 327171, 4 pages, 2011.

16. Maria Matsagoura, Emanouil Andreadis, Emanouil J. Diamantopoulos, Charalambos Vassilopoulos, Nicholas Tentolouris, Nicholas Katsilambros Carotid IntimaMedia Thickness in Patients With Type 2 Diabetes Diabetes Care Oct 2003;26(5):2966-69.

17. Louise Lundby-ChristThomas P Almdal, Bendix Carstensen, Lise Tarnow, Niels Wiinberg. Carotid intima-media thickness in individuals with and without type 2 diabetes: a reproducibility study. Cardiovascular Diabetology 2010,9(5):40.

18. Gómez-Marcos MA, Recio-Rodríguez JI, RodríguezSánchez E, Patino-Alonso MC, Magallón-Botaya R, Martínez-Vizcaino V, Gómez Sánchez L, García-Ortiz L. Carotid intima-media thickness in diabetics and hypertensive patients. Rev Esp Cardiol. 2011;64(7):6225.

19. Bonithon-Kopp C, Touboul PJ, Berr C, Leroux C, Mainard F, Courbon D, Ducimetière P. Relation of intima-media thickness to atherosclerotic plaques in carotid arteries. The Vascular Aging (EVA) Study. Arterioscler Thromb Vasc Biol. 1996;16(2):310-6.

20. Mackinnon AD, Jerrard-Dunne P, Sitzer M, Buehler A, von Kegler S, Markus HS. Rates and determinants of site-specific progression of carotid artery intima-media thickness: The carotid atherosclerosis progression study. Stroke. 2004;35(4):2150-4.

21. Adaikkappan M, Sampath R, Felix A, Sethupathy S. Evaluation of carotid atherosclerosis by B'mode ultrasonographic study in hypertensive patients compared with normotensive patients. Indian J Radiol Imaging [serial online] 2002;12(4):365-8.

22. Kota SK, Mahapatra GB, Kota SK, et al. Carotid intima media thickness in type 2 diabetes mellitus with ischemic stroke. Indian J Endocrinol Metab. 2013;17(4):716-722.

Source of Support: Nil; Conflict of Interest: None

Submitted: 06-07-2019; Accepted: 10-08-2019; Published online: 09-09-2019 